\title{
Knockdown of SNHG15 suppresses renal cell carcinoma proliferation and EMT by regulating the NF-кB signaling pathway
}

\author{
YANG DU ${ }^{1}$, CHUIZE KONG $^{1}$, YUYAN ZHU ${ }^{1}$, MENG YU ${ }^{2}$, ZELIANG LI $^{1}$, JIANBIN BI ${ }^{1}$, \\ ZHENHUA LI $^{1}$, XIANKUI LIU ${ }^{1}$, ZHE ZHANG $^{1}$ and XIUYUE YU ${ }^{1}$ \\ ${ }^{1}$ Department of Urology, The First Hospital of China Medical University, Shenyang, Liaoning 110001; \\ ${ }^{2}$ Department of Reproductive Biology and Transgenic Animal China Medical University, \\ Shenyang, Liaoning 110003, P.R. China
}

Received November 23, 2017; Accepted April 12, 2018

DOI: 10.3892/ijo.2018.4395

\begin{abstract}
Aberrant expression of long noncoding RNAs (lncRNAs) is associated with cancer tumorigenesis and progression. It has been suggested that lncRNAs may be potential clinical diagnostic and prognostic biomarkers, and therapeutic targets. In the present study, the expression levels of small nucleolar RNA host gene 15 (SNHG15) were significantly upregulated in renal cell carcinoma (RCC) tissues and cell lines compared with in adjacent tissues and a proximal tubule epithelial cell line, as determined by reverse transcription-quantitative polymerase chain reaction. Subsequently, knockdown of SNHG15 expression with small interfering RNA inhibited RCC proliferation, invasion and migration, was determined by western blotting and Transwell assays. Furthermore, the present study suggested that SNHG15 may be involved in the nuclear factor- $\kappa \mathrm{B}$ signaling pathway, induce the epithelial-mesenchymal transition process, and promote RCC invasion and migration.
\end{abstract}

\section{Introduction}

Renal cell carcinoma ( $\mathrm{RCC}$ ) is one of the most common malignancies of the urological system, which leads to $\sim 100,000$ cases of mortality each year (1). Each year in China, per 1,000 new cases of cancer, 66.8 cases are caused by RCC; and per 1,000 cases of cancer-associated mortality, 23.4 cases are caused by RCC (2). Due to the lack of obvious clinical symptoms in the early stages of RCC, once diagnosed it may already have metastasized to other organs. Tumorigenesis and metastasis of RCC are extremely complex, not only with regards to genetic mutations, but also in the imbalance between tumor suppressor and activation pathways (3). At present, there are no available molecular biomarkers for RCC; therefore, the

Correspondence to: Professor Chuize Kong, Department of Urology, The First Hospital of China Medical University, 155 Nanjing North Street, Shenyang, Liaoning 110001, P.R. China

E-mail: kongchuize_cmu@sina.cn

Key words: long noncoding RNA, SNHG15, nuclear factor- $\kappa \mathrm{B}$, epithelial-mesenchymal transition, renal cell carcinoma identification of more specific, effective biomarkers and therapeutic targets for RCC is required.

Long noncoding RNAs (lncRNAs) are >200 nt non-coding transcripts (4). It has been reported that lncRNAs have important roles in cellular development, differentiation, and numerous other biological, physiological and pathological processes (5). Previous studies have revealed that aberrant expression of lncRNAs is involved in tumorigenesis and progression $(6,7)$. For example, HOX transcript antisense RNA (HOTAIR) has been reported to be involved in various types of cancer. HOTAIR recruits the poly-comb repressive complex 2 and lysine-specific histone demethylase $1 \mathrm{~A}$, thus leading to hypermethylation of histone H3 lysine 27 and ectopic expression of oncogenes (8). In addition, metastasis-associated lung adenocarcinoma transcript 1 (MALAT1) may facilitate an aggressive phenotype via the enhancer of zeste homolog 2 pathway, and may interact with microRNA (miR)-205 in RCC (9). Conversely, downregulation of MALAT1 leads to a decrease in the expression levels of epithelial-mesenchymal transition (EMT)-associated genes, including including zinc finger E-box-binding homeobox (ZEB)1, ZEB2 and Slug, and an increase in cadherin $1(10,11)$. Functional lncRNAs can be used for cancer diagnosis and the determination of prognosis, and may be considered potential therapeutic targets (12). Small nucleolar RNA host gene 15 (SNHG15) is a long intergenic noncoding RNA, which is located on chromosome $7 \mathrm{p} 13$ and yields an $837 \mathrm{bp}$ transcript. Ectopic expression of SNHG15 promotes cell proliferation and invasion, partly by regulating matrix metalloproteinase (MMP)2 and MMP9 expression (13). However, the function of SNHG15 in RCC, as well as its regulatory mechanism, remains to be elucidated.

The present study demonstrated that SNHG15 expression was upregulated in RCC tissues and cell lines. Furthermore, knockdown of SNHG15 expression using small interfering (si)RNA inhibited cell proliferation, invasion and migration, and promoted apoptosis. The results indicated that SNHG15 may promote cell EMT by modulating the nuclear factor $(\mathrm{NF})-\kappa \mathrm{B}$ pathway.

\section{Materials and methods}

Cell lines. The human RCC cell lines ACHN, OSRC-2, 786-O, 769-P and CAKI-1, and the normal kidney proximal tubule 
epithelial cell line HK-2 were obtained from the Chinese Academy of Sciences, Type Culture Collection Cell Bank (Shanghai, China). 769-P, 786-O and OSRC-2 cells were cultured in RPMI-1640 medium (HyClone; GE Healthcare, Logan, UT, USA); ACHN cells were cultured in minimal essential medium with Earle's balanced salts (HyClone; GE Healthcare); CAKI-1 cells were cultured in McCoy's 5A medium (Gibco; Thermo Fisher Scientific, Inc., Waltham, MA, USA); and HK-2 cells were cultured in Dulbecco's modified Eagle's medium/F12 (HyClone; GE Healthcare). All media were supplemented with $10 \%$ fetal bovine serum (FBS; Biological Industries, Beit-Haemek, Israel), 100 U/ $\mathrm{ml}$ penicillin and $100 \mathrm{mg} / \mathrm{ml}$ streptomycin (TBD Science, Tianjin, China). Cells were cultured at $37^{\circ} \mathrm{C}$ in an atmosphere containing $5 \% \mathrm{CO}_{2}$.

Tissue samples and clinical data collection. The present study obtained tumor and adjacent normal tissue samples from 96 patients who were diagnosed with RCC and underwent surgical resection at the First Affiliated Hospital of Chinese Medical University (Shenyang, China) between February and July 2017. The present study was approved by the Ethics Committee on Human Research of the First Affiliated Hospital of Chinese Medical University, and written informed consent was obtained from all patients. The collected tissue samples were stored at $-80^{\circ} \mathrm{C}$ prior to use.

$R N A$ preparation and reverse transcription-quantitative polymerase chain reaction ( $R T-q P C R)$. Total RNA was extracted from clinical samples and cultured cells using RNAiso Plus (Takara Biotechnology Co., Ltd., Dalian, China). Total RNA was quantified using a BioDrop Duo UV/VIS spectrophotometer (BioDrop Ltd., Cambridge, UK); only samples with an optical density A260/A280 ratio close to 2.0 were subsequently analyzed. According to the manufacturer's protocol, cDNA was synthesized using PrimeScript ${ }^{\mathrm{TM}}$ RT Master Mix, and qPCR was performed using SYBR Premix Ex Taq ${ }^{\mathrm{TM}}$ (both from Takara Biotechnology Co., Ltd.). The assay was performed using a LightCycler ${ }^{\mathrm{TM}} 480$ II system (Roche Diagnostics, Basel, Switzerland) as follows: $50^{\circ} \mathrm{C}$ for $2 \mathrm{~min}$, $95^{\circ} \mathrm{C}$ for $10 \mathrm{~min}, 45$ cycles at $95^{\circ} \mathrm{C}$ for $10 \mathrm{sec}, 60^{\circ} \mathrm{C}$ for $30 \mathrm{sec}$ and $72^{\circ} \mathrm{C}$ for $45 \mathrm{sec}$. After 45 cycles, a melting curve was obtained by increasing the temperature from 40 to $97^{\circ} \mathrm{C}$ at a rate of $0.4^{\circ} \mathrm{C} / \mathrm{sec}$ under continuous fluorescence monitoring. All data were normalized to the expression of $\beta$-actin. The relative expression levels were evaluated using the $2^{-\Delta \Delta \mathrm{Cq}}$ method (14). The primer sequences used to detect target genes and the internal reference gene were as follows $\left(5^{\prime}-3^{\prime}\right)$ : $\beta$-actin, forward, catgtacgttgctatccaggc and reverse, ctccttaatgtcacgcacgat; and SNHG15, forward, gcaccttaattgagcaagt and reverse, ttcattcaggagataccagaa.

siRNA transfection. 786-O cells and ACNH cells were seeded in 6-well plates at a density of 400,000 cells/well, and were transfected with two effective SNHG15 siRNAs (Shanghai GenePharma Co., Ltd., Shanghai, China) at a concentration of $100 \mathrm{nM}$, using Lipofectamine ${ }^{\circledR} 3000$ transfection reagent (Invitrogen; Thermo Fisher Scientific, Inc.), for $72 \mathrm{~h}$ at $37^{\circ} \mathrm{C}$, according to the manufacturer's protocol. The culture medium was replaced $6 \mathrm{~h}$ post-transfection. The siRNA and negative control (NC) siRNA sequences used were as follows $\left(5^{\prime}-3^{\prime}\right)$ : siRNA-1, sense, GCAGUCUUUGUCCAUGAAATT and antisense, UCAUGGACAAAGACUGCTT; siRNA-2, sense, GCA GCAAUCCCAAGAUGCUTT and antisense, AGCAUCUUG GGAUUGCUGCTT; and NC, sense, UUCUCCGAA CGUGUC ACGUTT and antisense, ACGUGACACGUUCGGAGAATT.

Western blotting. A total of $72 \mathrm{~h}$ post-transfection, cells were washed twice with ice-cold PBS, and lysed on ice in 10X (wt/vol) radioimmunoprecipitation assay lysis buffer containing $1 \mathrm{mM}$ phenylmethylsulfonyl fluoride (Beyotime Institute of Biotechnology, Shenzhen, China). The lysate was then centrifuged at $13,400 \mathrm{x}$ g for $30 \mathrm{~min}$ at $4^{\circ} \mathrm{C}$. The supernatant was collected and stored at $-80^{\circ} \mathrm{C}$. The concentration of protein samples was measured using a bicinchoninic acid assay (Beyotime Institute of Biotechnology). After denaturation, equal amounts of protein ( $30 \mu \mathrm{g} / \mathrm{lane})$ were separated by $10 \%$ SDS-PAGE and transferred to polyvinylidene fluoride membranes (EMD Millipore, Billerica, MA, USA). Nonspecific binding was blocked with $5 \%$ bovine serum albumin (BSA; Beijing Solarbio Science \& Technology Co., Ltd., Beijing, China) in Tris-buffered saline containing $0.1 \%$ Tween-20 (TBST), and primary antibodies were applied to the membranes overnight at $4^{\circ} \mathrm{C}$ in 5\% BSA with TBST.Monoclonal primary antibodies were specific to Snail $(1: 1,000,3879)$, Slug $(1: 1,000,9585)$, Vimentin $(1: 1,000,5741)$, E-cadherin $(1: 1,000,14472), \mathrm{N}$-cadherin $(1: 1,000,13116)$ and Histone H3 $(1: 2,000,4499)$ (all from Cell Signaling Technology, Inc., Danvers, MA, USA), ZEB1 (1:500, BA2871-2; Wuhan Boster Biological Technology, Ltd., Wuhan, China), $\beta$-actin (1:5,000, A1978), GAPDH (1:5,000, G9545) (both from Sigma-Aldrich; Merck KGaA, Darmstadt, Germany) and NF- $\kappa$ B1 (p50) (1:1,000, 14220-1-AP; Wuhan Sanying Biotechnology, Wuhan, China). After washing three times with TBST for $10 \mathrm{~min}$ per wash, the membranes were incubated for $2 \mathrm{~h}$ at $37^{\circ} \mathrm{C}$ with rabbit immunoglobulin $\mathrm{G}$ secondary antibodies $(1: 5,000$, ZB-2301 and ZB-2305; OriGene Technologies, Inc., Beijing, China). The proteins were detected using an EasySee ${ }^{\circledR}$ Western Blot kit (Beijing Transgen Biotech Co., Ltd., Beijing, China), according to the manufacturer's protocol. The densitometric values were calculated using ImageJ version $1.50 \mathrm{i}$ software (National Institutes of Health, Bethesda, MD, USA).

Cell proliferation assay. Cells were seeded in 96-well plates at a density of $2 \times 10^{3}$ cells/well and were transfected with SNHG15 NC siRNAs for $72 \mathrm{~h}$ in situ. The Cell Counting Kit-8 (CCK-8) assay (Dojindo Molecular Technologies, Inc., Shanghai, China) was used to assess proliferative potential, according to the manufacturer's protocol. The absorbance was measured at $450 \mathrm{~nm}$ every $24 \mathrm{~h}$ using a plate reader (Model 680; Bio-Rad Laboratories, Inc., Watford, UK). Three replicates were tested for each time-point and each assay was repeated at least three times.

Cell proliferation was also evaluated using a Cell-Light 5-ethynyl-2'-deoxyuridine (EdU) DNA cell proliferation kit (Guangzhou RiboBio Co., Ltd., Guangzhou, China). EdU was added to the culture medium at a concentration of $40 \mu \mathrm{M}$ for $12 \mathrm{~h}$ at $37^{\circ} \mathrm{C}$. Following fixation in $4 \%$ paraformaldehyde for $30 \mathrm{~min}$ at room temperature and treatment with $0.5 \%$ Triton-X for $30 \mathrm{~min}$ at $37^{\circ} \mathrm{C}$, cells were incubated for $1 \mathrm{~h}$ with Apollo 
reaction cocktail in a dark room at room temperature. Prior to observation under a fluorescence microscope, nuclei were stained with Hoechst 33342. The exposure time for visualization of Apollo was $28 \mathrm{sec}$, and that for nuclei was $175 \mathrm{msec}$.

Cell cycle analysis and cell apoptosis assay. Cell apoptosis was examined using flow cytometry. The cells were seeded, transfected for $72 \mathrm{~h}$, and collected from a 6-well plate and washed with ice-cold PBS and resuspended with binding buffer at a density of $1 \times 10^{6} / \mathrm{ml}$. The cells were then stained with fluorescein isothiocyanate (FITC) Annexin V and propidium iodide (PI) (BD Pharmingen ${ }^{\text {TM }}$ Annexin V/FITC apoptosis kits; BD Biosciences, San Jose, CA, USA). Flow cytometric analysis was performed using a FACSCalibur flow cytometer equipped with CellQuest version 6.0 software (both from BD Biosciences).

For cell cycle analysis, cells were dissociated, collected and washed with PBS and then fixed in ice-cold 75\% ethanol. $\mathrm{PI} / \mathrm{RNase}$ staining buffer (BD Biosciences) was added, and the cells at a density of $1 \times 10^{6} / \mathrm{ml}$ were incubated in the dark for $20 \mathrm{~min}$ at room temperature. Cell cycle analysis was performed with a FACSCalibur flow cytometer (BD Biosciences) and data were analyzed by ModFit LT version 4.0.5 (Verity Software House, Inc., Topsham, ME, USA). Each experiment was performed in triplicate.

Transwell assay. For cell invasion assays, Transwell chambers with $8-\mu \mathrm{m}$ pores coated with Matrigel (BD Biosciences) were inserted into a 24-well plate (Costar; Corning Incorporated, Corning, NY,USA), whereas for the migration assays, Transwell chambers without Matrigel were used. Post-transfection with SNHG15 and NC siRNAs for $72 \mathrm{~h}$, cells were trypsinized and resuspended in RPMI-1640 containing 1\% FBS. Subsequently, $0.2 \mathrm{ml}$ cell suspension $\left(1 \times 10^{4} / \mathrm{ml}\right)$ was added to the upper chamber, and $0.6 \mathrm{ml}$ RPMI-1640 containing 10\% FBS was added to the lower chamber. After incubation for $24 \mathrm{~h}$ at $37^{\circ} \mathrm{C}$, the cells remaining in the upper chamber were removed using cotton swabs, and those that had migrated to the lower side were fixed with $4 \%$ paraformaldehyde for $10 \mathrm{~min}$, and stained with $1.0 \%$ crystal violet for $10 \mathrm{~min}$ at room temperature. Images were captured using an EVOS ${ }^{\mathrm{TM}}$ XL Core Imaging system (Invitrogen; Thermo Fisher Scientific, Inc.).

Nuclear/cytoplasmic fractionation. Nuclear extracts were obtained using the Nuclear Extraction kit (Abcam, Cambridge, MA, USA). Post-transfection for $72 \mathrm{~h}$, cells were washed with ice-cold PBS, and incubated in pre-extraction buffer on ice for $10 \mathrm{~min}$. Subsequently, extracts were collected and centrifuged at 13,400 x $\mathrm{g}$ for $1 \mathrm{~min}$. The supernatants containing cytoplasmic protein were collected and $10 \mu \mathrm{l}$ extraction buffer was added to the pellet, which was mixed and incubated on ice for $15 \mathrm{~min}$. The nuclear extracts in the supernatants were collected following centrifugation at $13,400 \mathrm{x}$ g for $15 \mathrm{~min}$ at $4^{\circ} \mathrm{C}$. The cytoplasmic and nuclear protein extracts were used for subsequent western blotting.

Tumor necrosis factor (TNF)- $\alpha$ treatment. TNF- $\alpha$ (Sino Biological, Inc., Beijing, China) was reconstituted at $10 \mu \mathrm{g} / \mu \mathrm{l}$ with PBS. Post-transfection for $72 \mathrm{~h}$, cells were cultured with serum-free medium for $12 \mathrm{~h}$. TNF- $\alpha$ solution was diluted in serum-free medium to a concentration of $50 \mathrm{ng} / \mathrm{ml}$ and added to the culture flasks. PBS (1X) solution, at the same volume as TNF- $\alpha$, was used to treat the control group, and was also diluted in serum-free medium. Subsequently, the treatment and control groups were cultured at $37^{\circ} \mathrm{C}$.

Immunofluorescence. Immunofluorescence images were captured under an inverted fluorescence microscope (Olympus Corporation, Tokyo, Japan). Cells were seeded in 24-well plates at a density of $6 \times 10^{4} /$ per well and were transfected with SNHG15 and NC siRNAs for $72 \mathrm{~h}$, after which the cells were cultured with serum-free medium for $12 \mathrm{~h}$ at $37^{\circ} \mathrm{C}$ and treated with $50 \mathrm{ng} / \mathrm{ml} \mathrm{TNF}-\alpha$ for $6 \mathrm{~h}$ at $37^{\circ} \mathrm{C}$. Subsequently, cells were fixed with $4 \%$ paraformaldehyde for $30 \mathrm{~min}$ at room temperature, permeabilized in $0.2 \%$ Triton $\mathrm{X}-100$ for $30 \mathrm{~min}$ at $37^{\circ} \mathrm{C}$ and blocked with $5 \% \mathrm{BSA}$ for $30 \mathrm{~min}$ at $37^{\circ} \mathrm{C}$. Cells were then incubated with a rabbit polyclonal antibody against $\mathrm{NF}-\kappa \mathrm{B} 1$ (1:200, 14220-1-AP; Wuhan Sanying Biotechnology) in blocking buffer overnight. Subsequently, cells were warmed at $37^{\circ} \mathrm{C}$ for $1 \mathrm{~h}$, and were incubated with Alexa Fluor ${ }^{\circledR} 488$-conjugated antibody (1:500, ZF-0511; OriGene Technologies, Inc.) at $37^{\circ} \mathrm{C}$ for $1 \mathrm{~h}$ in the dark. Prior to visualization, the nuclei were stained with DAPI (Beyotime Institute of Biotechnology).

Bioinformatics analysis. lncRNA expression data were derived from the The Atlas of Noncoding RNAs in Cancer (TANRIC) database (http://ibl.mdanderson.org/tanric/_ design/basic/index.html), which provides easy access to publicly available RNA-Seq data for IncRNA expression, based on The Cancer Genome Atlas (TCGA) data portal. According to the TANRIC RCC database, IncRNA expression was analyzed for 612 patients (67 normal tissue samples and 545 RCC tissue samples). lncRNA expression values were obtained as $\log _{2}$ reads per kilobase per million mapped reads (RPMK) from the TANRIC database, and the median expression was calculated for benign and tumor samples, and is visualized in boxplots.

Due to the lack of prognostic information in the aforementioned TANRIC database, Kaplan-Meier curves were obtained from another TCGA database tool (http://www. oncolnc.org/) using the Kidney Renal Clear Cell Carcinoma database. The lower percentile was set as 10 , and the upper as 90; Kaplan-Meier analysis was performed based on these data. Log-rank (Mantel-Cox text) was used to compare the difference between the high and low expression groups.

Data were also obtained from the publicly available Gene Expression Omnibus (GEO, http://www.ncbi.nlm.nih.gov/geo/). The GSE53757 dataset was used (15); probe, 225699_at. GEO2R (https://www.ncbi.nlm.nih.gov/geo/geo2r/) was used to compare the tumor group with the normal group.

The possibility of protein and lncRNA binding was predicted using the AnnoLnc website (http://annolnc.cbi.pku. edu.cn/). The full sequence of SNHG15 was typed in fasta format and the potential proteins that bind with SNHG15 were listed. Subsequently, the probability of these interactions was confirmed using the bioinformatics website, RPISeq (http://pridb.gdcb.iastate.edu/RPISeq/index.html); the two calculated values [prediction using Random Forest (RF) classifier, 0.75; prediction using Support Vector Machine (SVM) classifier, 0.59] indicated high binding potency. RPISeq predic- 
tions were based on RF and SVM classifiers. The interaction probabilities generated by RPISeq range between 0 and 1; in performance evaluation experiments, predictions with probabilities $>0.5$ are considered 'positive', thus indicating that the corresponding RNA and protein are likely to interact.

Statistical analysis. Two-tailed t-test was used for analysis of data obtained from the TANRIC database, and paired sample t-test was used for analysis of data from the GEO database. The association between T stage and SNHG15 expression was calculated by Fisher's exact test, whereas the association between other clinical characteristics and SNHG15 expression was assessed by the $\chi^{2}$ test. One-way analysis of variance followed by Dunnett's multiple comparisons tests or Turkey's multiple comparisons tests were used to compare differences among multiple groups and to compare SNHG15 expression in various RCC cell lines. $\mathrm{P}<0.01$ was considered to indicate a statistically significant difference. The results of assays repeated in triplicate are presented as the means \pm standard deviation, unless otherwise stated. Statistical analyses were performed using the Statistical Package for the Social Sciences software package 21.0 (SPSS 21.0; IBM Corporation, Armonk, NY, USA).

\section{Results}

SNHG15 is upregulated in RCC tissues and cell lines. SNHG15 expression in 67 normal tissue samples and 545 RCC tissue samples was obtained from the TANRIC database. SNHG15 was significantly upregulated in RCC tissues $\left(\log _{2}\right.$ RPMK $\left.=3.278\right)$ compared with in the normal tissues $\left(\log _{2} \mathrm{RPMK}=1.261 ; \mathrm{P}<0.01\right.$; Fig. 1A). Subsequently, the prognostic information for patients with RCC was collected from the OncoLnc website, and patients were categorized into high and low expression groups, based on median SNHG15 expression. The number of patients in the low expression group was 52, whereas that in the high expression group was 470. The results of a Kaplan-Meier analysis revealed that patients with higher SNHG15 expression had poorer survival tendency $(\mathrm{P}<0.01$; Fig. 1B). In addition, SNHG15 expression was analyzed using a GEO dataset (GSE53757). Among the microarray data (15), the expression levels of SNHG15 were upregulated in RCC $(\mathrm{P}<0.01$; Fig. 1C). Furthermore, the expression levels of SNHG15 were detected in 96 paired RCC and adjacent normal tissue samples obtained from the First Hospital of China Medical University, using RT-qPCR. The tumor/adjacent normal tissue expression values were calculated, and samples were categorized into two groups according to the cut-off point (1.0). The number of patients with high SNHG15 expression was larger than those with low expression (Fig. 2A). As shown in Table I, clinical characteristics were analyzed in the high and low SNHG15 expression groups, which were divided according to the median value of SNHG15 relative expression. The patients with expression higher than the median value were included in the high expression group, whereas the patients with expression lower than the median value were included in the low expression group. The high expression group exhibited reduced differentiation and advanced $\mathrm{T}$ stage compared with in the low expression group. The number of cases with lymphatic invasion or metastasis was too small to provide meaningful statistical results. Furthermore, SNHG15 expression was measured in RCC cell lines: ACHN, CAKI-1, OSRC-2, 769-P and 786-O cells,
Table I. Association between SNHG15 expression and the clinical characteristics of patients with renal cell carcinoma.

\begin{tabular}{|c|c|c|c|}
\hline \multirow[b]{2}{*}{ Characteristic } & \multicolumn{2}{|c|}{ SNHG15 } & \multirow[b]{2}{*}{ P-value } \\
\hline & $\begin{array}{l}\text { High } \\
(n=48)\end{array}$ & $\begin{array}{c}\text { Low } \\
(n=48)\end{array}$ & \\
\hline Age (years) & & & 0.207 \\
\hline$>60$ & 28 & 23 & \\
\hline$\leq 60$ & 20 & 25 & \\
\hline Sex & & & 0.270 \\
\hline Male & 27 & 23 & \\
\hline Female & 21 & 25 & \\
\hline T stage & & & $0.006^{\mathrm{a}}$ \\
\hline $\mathrm{T} 1(\mathrm{n}=70)$ & 28 & 42 & \\
\hline $\mathrm{T} 2(\mathrm{n}=16)$ & 11 & 5 & \\
\hline T3 (n=9) & 8 & 1 & \\
\hline $\mathrm{T} 4(\mathrm{n}=1)$ & 1 & 0 & \\
\hline Histological differentiation & & & $0.004^{\mathrm{a}}$ \\
\hline High & 17 & 33 & \\
\hline Middle & 19 & 11 & \\
\hline Low & 12 & 4 & \\
\hline Lymphatic invasion & 1 & 0 & - \\
\hline Distant metastasis & 1 & 0 & - \\
\hline
\end{tabular}

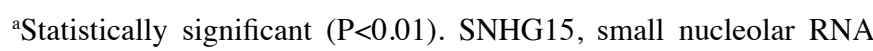
host gene 15 .

and in the normal renal cell line HK-2. There was a significant increase in the expression of SNHG15 in ACHN, CAKI-1, OSRC-2, 769-P and 786-O cells compared with in the HK-2 cells ( $\mathrm{P}<0.01$; Fig. 2B). The ACHN and 786-O cell lines exhibited the highest expression; therefore, these two cell lines were used for subsequent experimentation.

SNHG15 exerts a significant effect on RCC proliferation. The present study detected high SNHG15 expression in RCC; therefore, subsequent experiments were conducted in order to analyze its biological function. SNHG15 was upregulated in ACHN and 786-O cells; therefore, these cells were selected as the experimental cell lines. The knockdown effects of siRNAs targeting SNHG15 in RCC cells were confirmed through RT-qPCR ( $\mathrm{P}<0.01$; Fig. 3A). CCK-8 assays were also conducted to detect the effects of SNHG15 on cell proliferation. The results indicated that the proliferation of $\mathrm{ACHN}$ and 786-O cells was significantly inhibited following transfection with SNHG15 siRNAs $(\mathrm{P}<0.01$; Fig. 3B) compared with in the $\mathrm{NC}$ groups. Furthermore, the number of red-stained cells in the SNHG15 siRNA groups following EdU proliferation assays was reduced compared with in the NC groups (Fig. 3C). To investigate whether cell apoptosis was affected by SNHG15, flow cytometric analysis was conducted. The results demonstrated that the proportion of apoptotic cells was significantly increased in the SNHG15 knockdown groups compared with in the $\mathrm{NC}$ groups $(\mathrm{P}<0.01$; Fig. 3D). In addition, the effects 


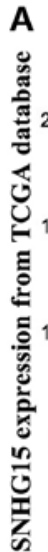
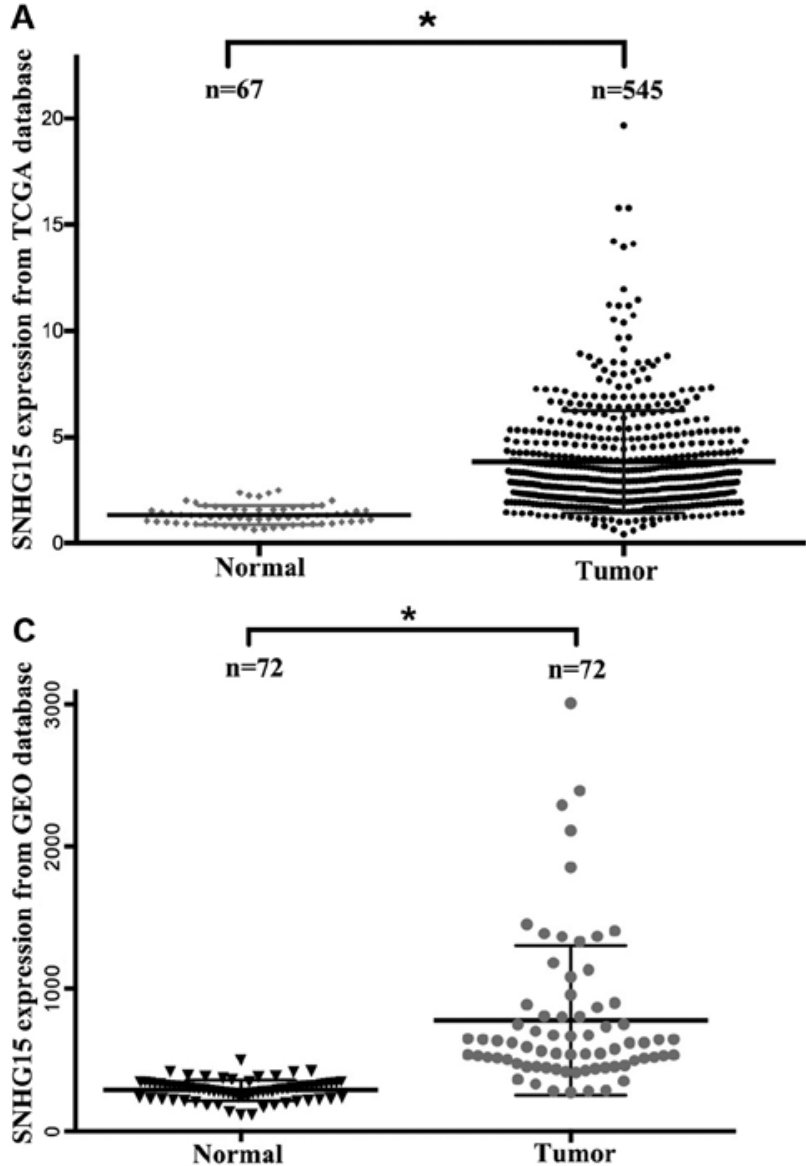

B

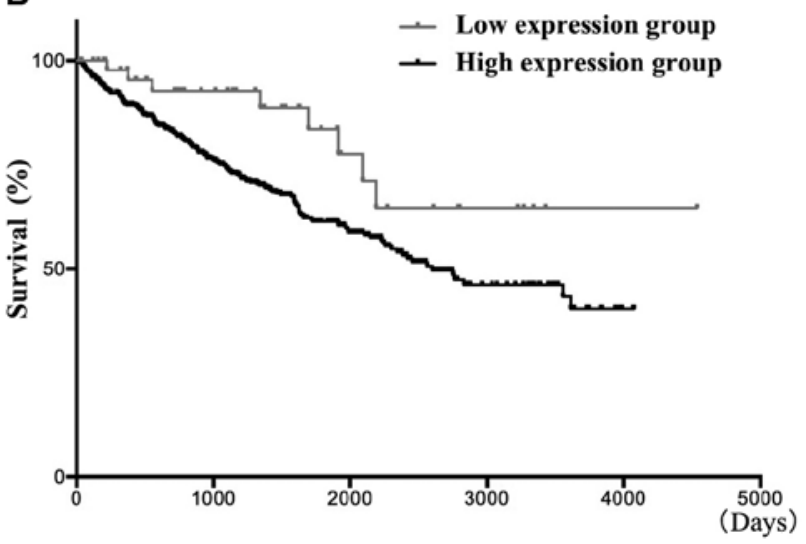

Figure 1. Differential expression of SNHG15 between RCC tissues and adjacent normal tissues from TCGA and GEO databases. (A) Expression of SNHG15 in RCC tumor tissues and adjacent normal tissues from TCGA database. (B) Kaplan-Meier overall survival curve analysis of patients with RCC; high expression and low expression groups were generated using a cut-off value of $1\left(\log _{2}\right)$. (C) Expression of SNHG15 in RCC tumor tissues and adjacent normal tissues from the GEO database. "P<0.01. GEO, Gene Expression Omnibus; RCC, renal cell carcinoma; SNHG15, small nucleolar RNA host gene 15; TCGA, The Cancer Genome Atlas.
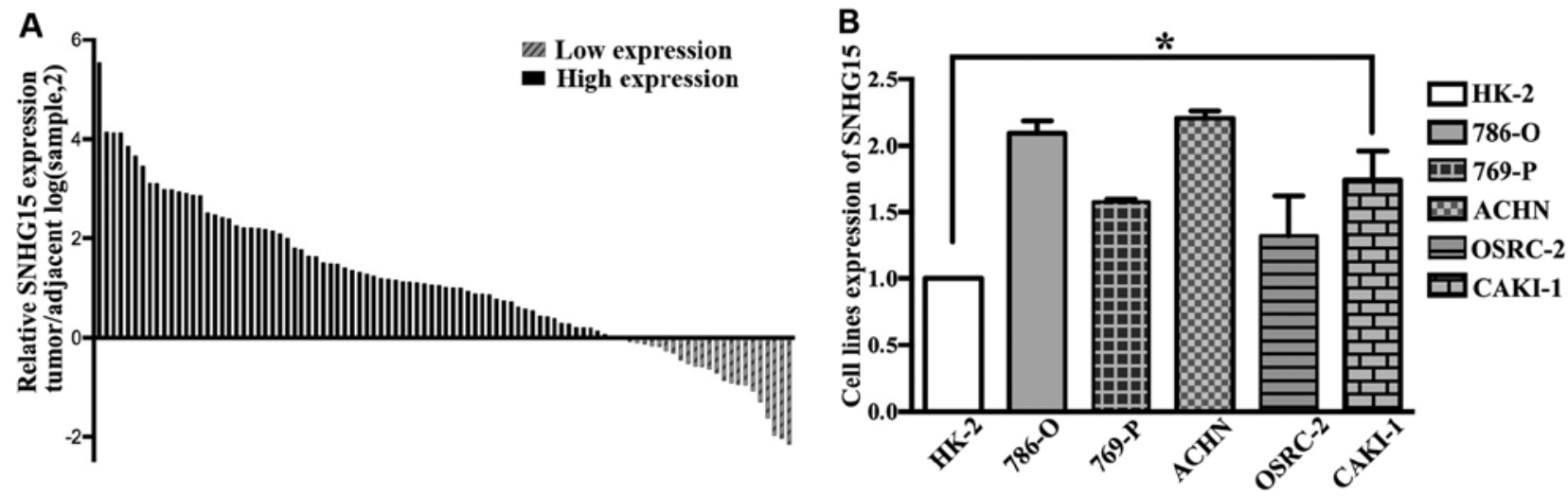

Figure 2. Expression levels of SNHG15 in RCC tissues and cell lines. (A) Relative expression of SNHG15 in RCC tumor tissues and adjacent normal tissues from 96 patients with RCC. (B) Relative expression of SNHG15 in RCC line (ACHN, 769-p, 786-O, OSRC-2 and CAKI-1) and the normal human renal cortex/proximal tubule epithelial cell line (HK-2), as analyzed by reverse transcription-quantitative polymerase chain reaction. ${ }^{*} \mathrm{P}<0.01$. RCC, renal cell carcinoma; SNHG15, small nucleolar RNA host gene 15.

of SNHG15 on cell cycle progression were examined by flow cytometric analysis. An increased accumulation of cells was detected in the G0/G1 phase, with a concomitant decrease in the number of cells in the S phase, post-transfection with SNHG15 siRNAs $(\mathrm{P}<0.01$; Fig. 3E). These results indicated that SNHG15 may promote the proliferation of RCC cells.
SNHG15 promotes RCC migration and invasion in vitro. Under a x10 optical microscope, the morphology of SNHG15 knockdown cells was revealed to be markedly different from that of NC cells. To distinguish between the two cell lines, which possessed similar morphology, different color balances were used. SNHG15 siRNA-transfected ACHN 

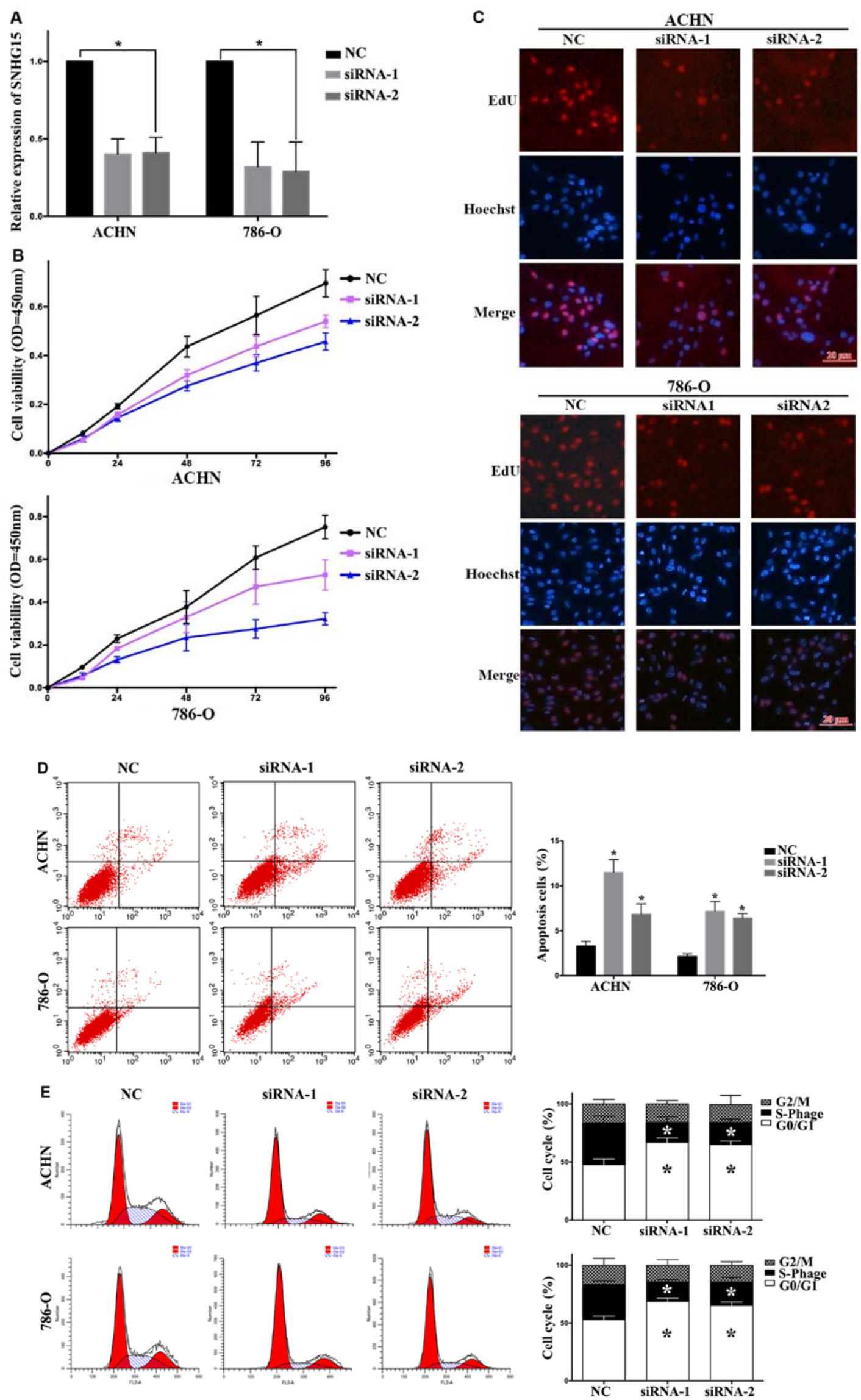

Figure 3. Effects of SNHG15 on RCC cell proliferation, apoptosis and cell cycle progression. (A) Reverse transcription-quantitative polymerase chain reaction analysis was conducted to detect SNHG15 expression in ACHN and 786-O cells post-transfection with NC and SNHG15 siRNAs. "P<0.01. (B) Cell counting kit-8 assays were conducted to investigate the proliferation of cells transfected with siRNAs. "P<0.01. (C) Proliferative capability of siRNA-transfected cells was evaluated using EdU staining immunofluorescence assays. (D) Flow cytometric detection of apoptosis by Annexin V-fluorescein isothiocyanate staining in cells transfected with siRNAs. "P<0.01. (E) Cell cycle analysis of siRNA-transfected cells by flow cytometry. "P<0.01. EdU, 5-ethynyl-2'-deoxyuridine; NC, negative control; OD, optical density; RCC, renal cell carcinoma; siRNA, small interfering RNA; SNHG15, small nucleolar RNA host gene 15. 
A
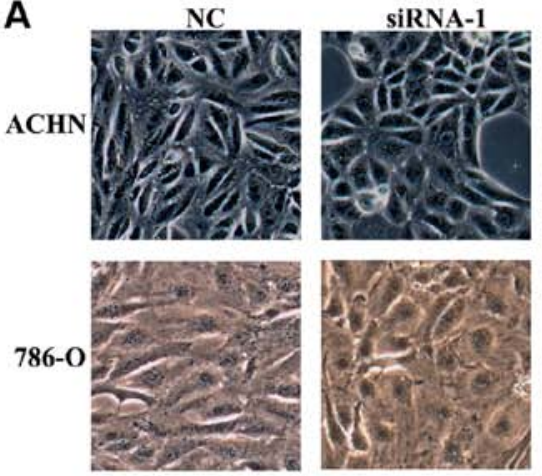

C
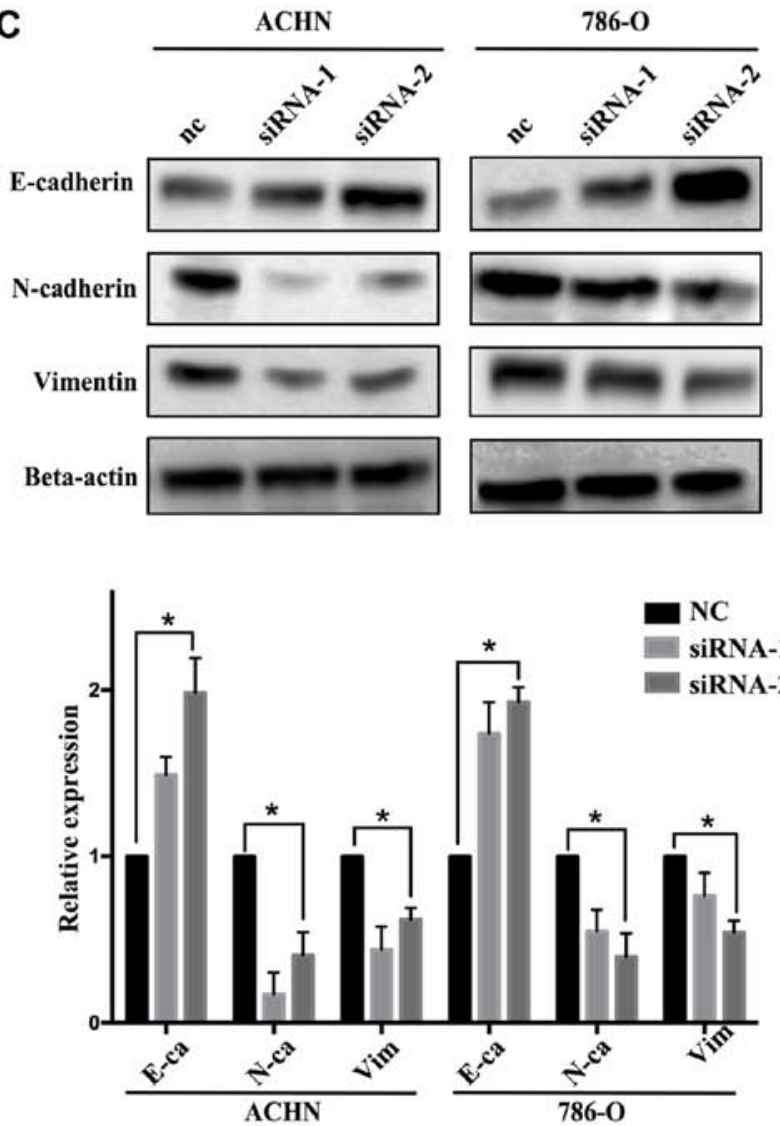
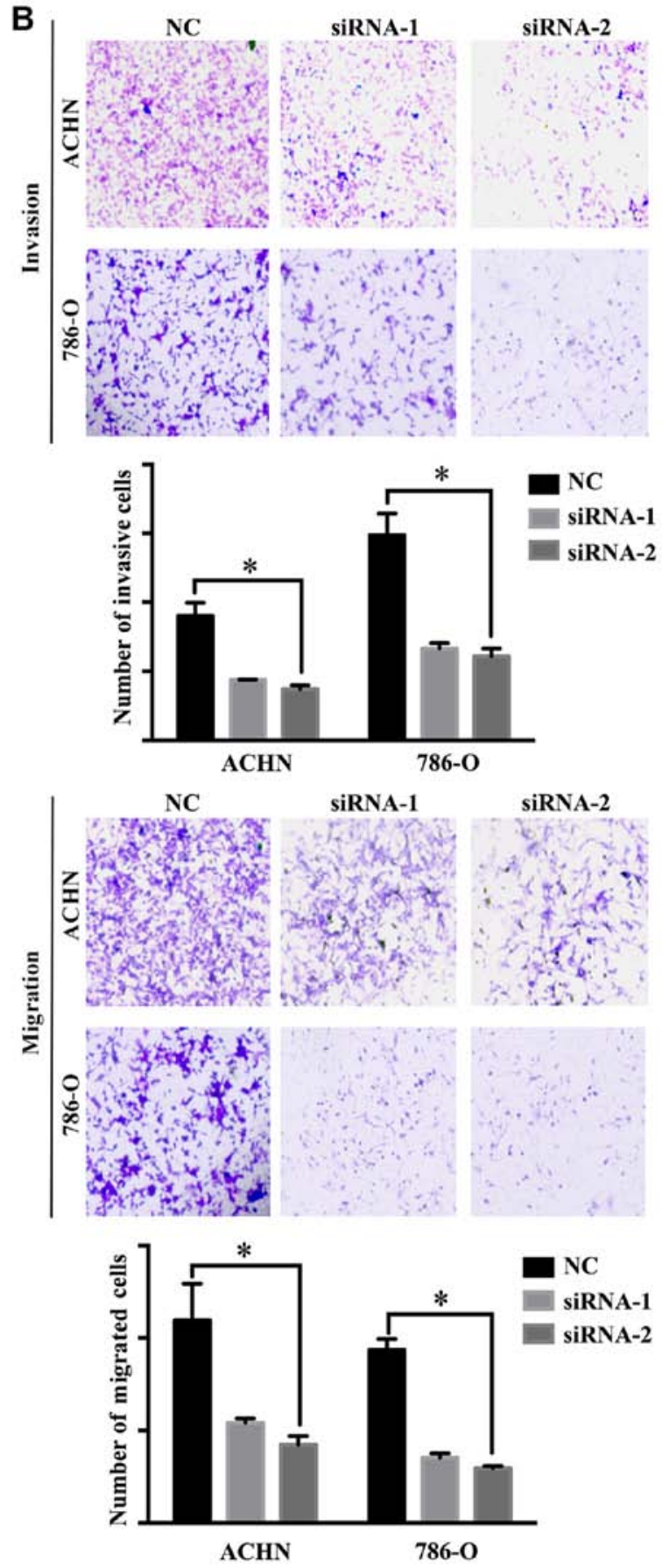

Figure 4. SNHG15 promotes renal cell carcinoma migration and invasion. (A) Morphological alterations of SNHG15 knockdown cells, as detected under an optical microscope (magnification, x10). (B) Transwell assays were used to determine the migration and invasion of ACHN and 786-O cells transfected with siRNAs (magnification, $\mathrm{x} 40$ ). ${ }^{*} \mathrm{P}<0.01$. (C) Expression levels of cell adhesion molecules (E-cadherin, $\mathrm{N}$-cadherin and Vimentin), as detected in $786-\mathrm{O}$ and ACHN cells. "P<0.01. NC, negative control; siRNA, small interfering RNA; SNHG15, small nucleolar RNA host gene 15.

cells exhibited diamond and polygon morphology, and cells were no longer long and fusiform in shape, whereas SNHG15 siRNA-transfected 786-O cells exhibited ellipse-shaped and ovoid morphology, and no longer possessed long and narrow fusiform morphology (Fig. 4A). These findings indicated that SNHG15 may contribute to the invasion and migration of RCC cells; therefore, these cells were assessed using Transwell assays. For ACHN and 786-O cell lines, the number of invaded cells was reduced in the knockdown groups compared with in the NC groups $(\mathrm{P}<0.01$; Fig. 4B). The migration assay exhibited similar results. These data suggested that SNHG15 may enhance invasion and migration of RCC cells. To examine the mechanism underlying the effects of SNHG15 on invasion and migration, the present study investigated EMT in RCC. The expression levels of three EMT markers (E-cadherin, $\mathrm{N}$-cadherin and Vimentin) were detected using western blotting. The results demonstrated that knockdown of SNHG15 decreased the expression levels of $\mathrm{N}$-cadherin and Vimentin, and increased E-cadherin expression $(\mathrm{P}<0.01$; Fig. $4 \mathrm{C})$. These results indicated that SNHG15 may induce the EMT process, and mediate RCC invasion and migration. 
A
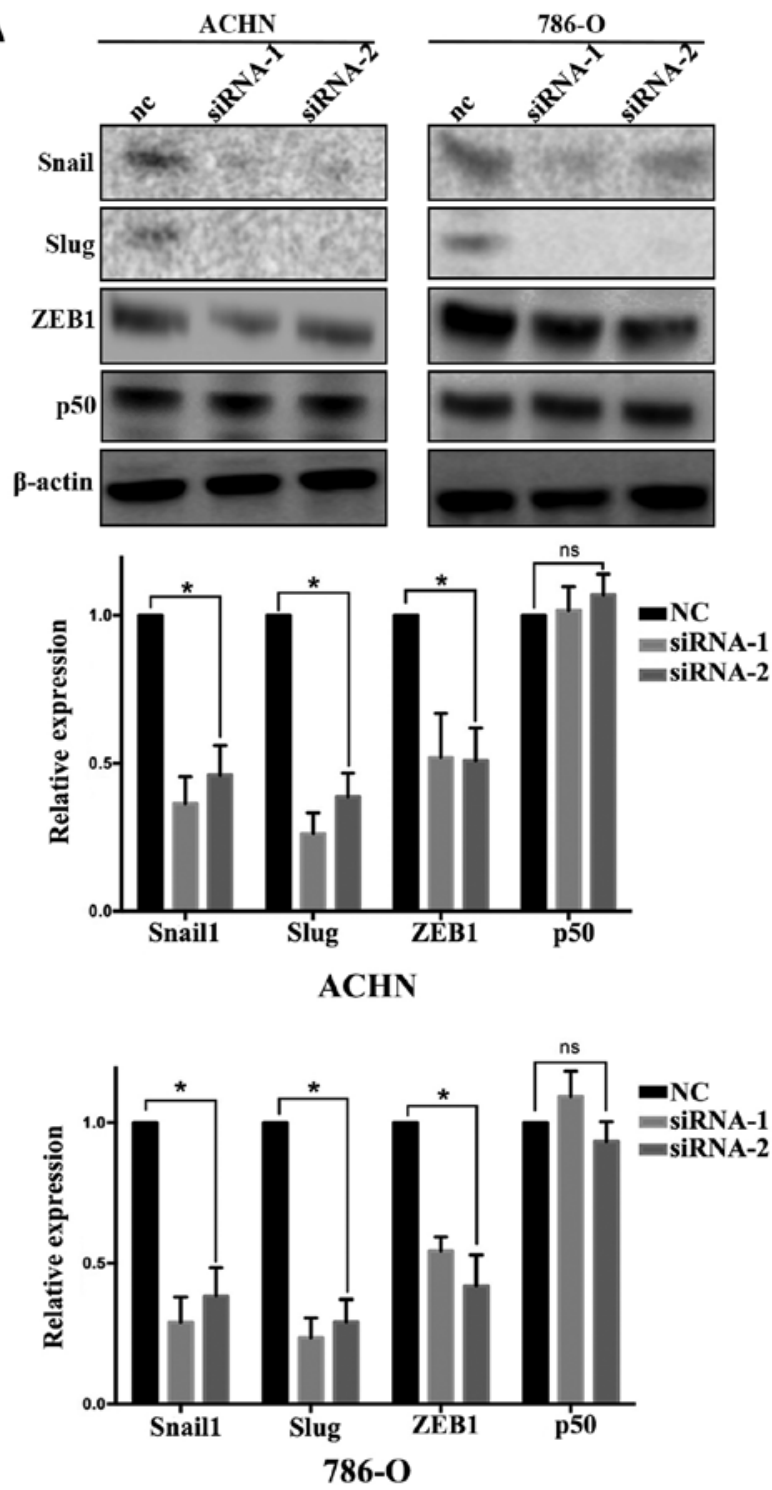

C
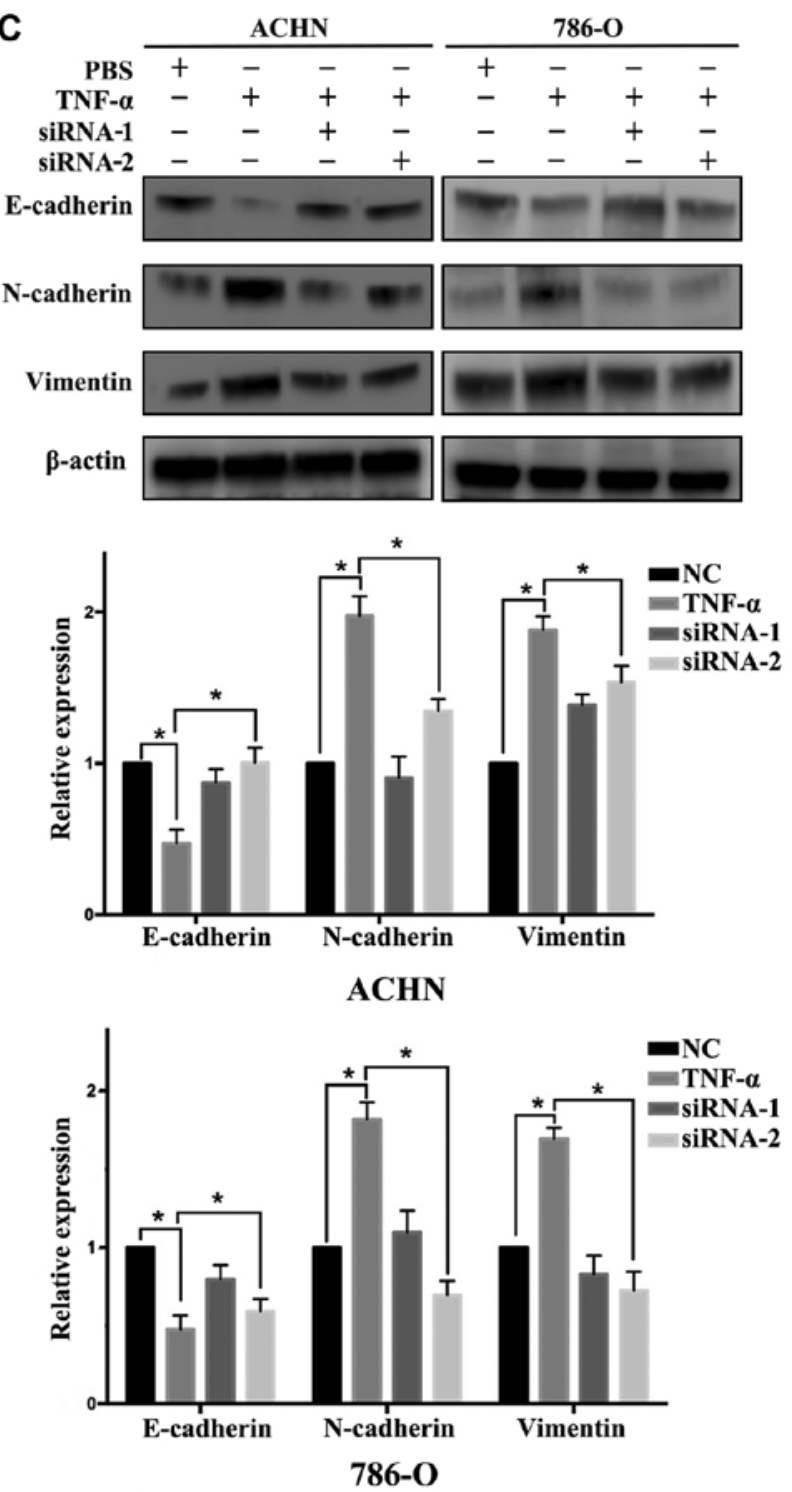
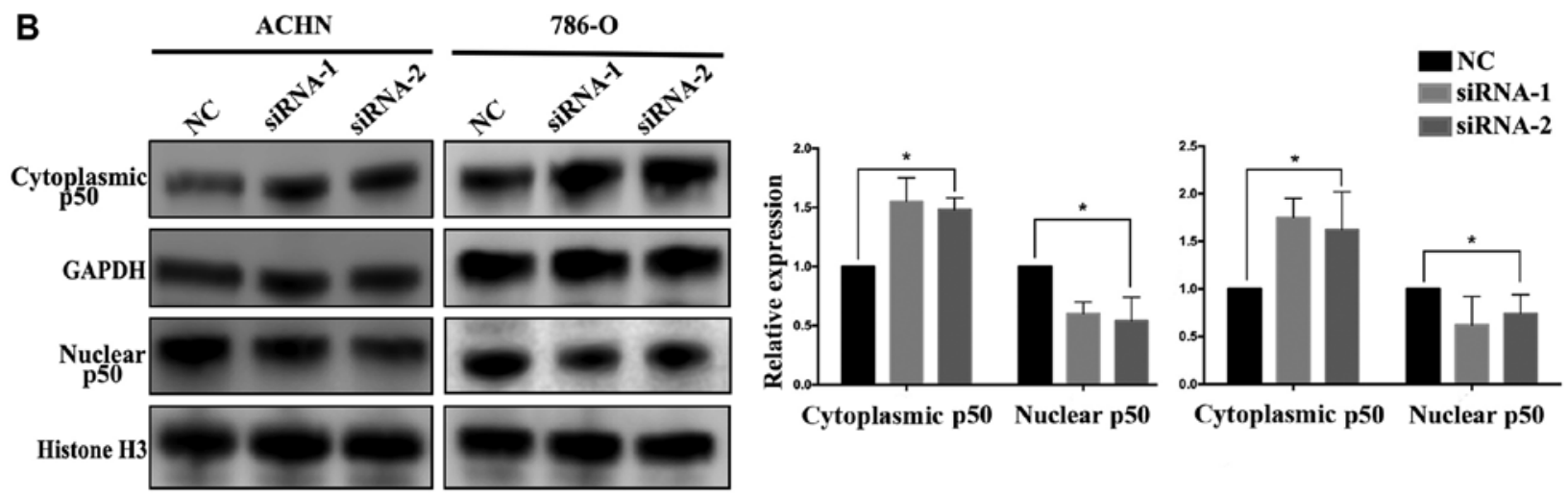

Figure 5. Knockdown of SNHG15 affects NF-kB entry into the nucleus. (A) Knockdown of SNHG15 reduced the protein expression levels of EMT-associated transcription factors (Snail1, Slug and ZEB1). However, there was no difference in the total protein expression levels of NF-kB between the SNHG15 siRNA and $\mathrm{NC}$ groups. ${ }^{*} \mathrm{P}<0.01$; ${ }^{\mathrm{ns}} \mathrm{P}>0.05$. (B) Nuclear/cytoplasmic NF- $\mathrm{kB}$ expression in ACHN and 786-O cells transfected with siRNAs. ${ }^{*} \mathrm{P}<0.01$. (C) Following stimulation with TNF- $\alpha$ for $6 \mathrm{~h}, \mathrm{EMT}$ markers were examined among the various groups. " $\mathrm{P}<0.01$.

SNHG15 regulates EMT via the $N F-\kappa B$ signaling pathway. To explore how SNHG15 contributes to EMT in RCC, the expression levels of transcription factors associated with EMT were detected. Western blotting was used to detect the expression of Snail1, Slug and ZEB1 in RCC; the expression levels of these three proteins were decreased in cells transfected with SNHG15 siRNA ( $\mathrm{P}<0.01$; Fig. 5A). These results suggested that Snaill, Slug and ZEB1 may be positively regulated by SNHG15 in RCC. Subsequently, bioinformatics data (http://annolnc.cbi.pku. edu.cn/) were analyzed, which indicated that NF-кB1 response 

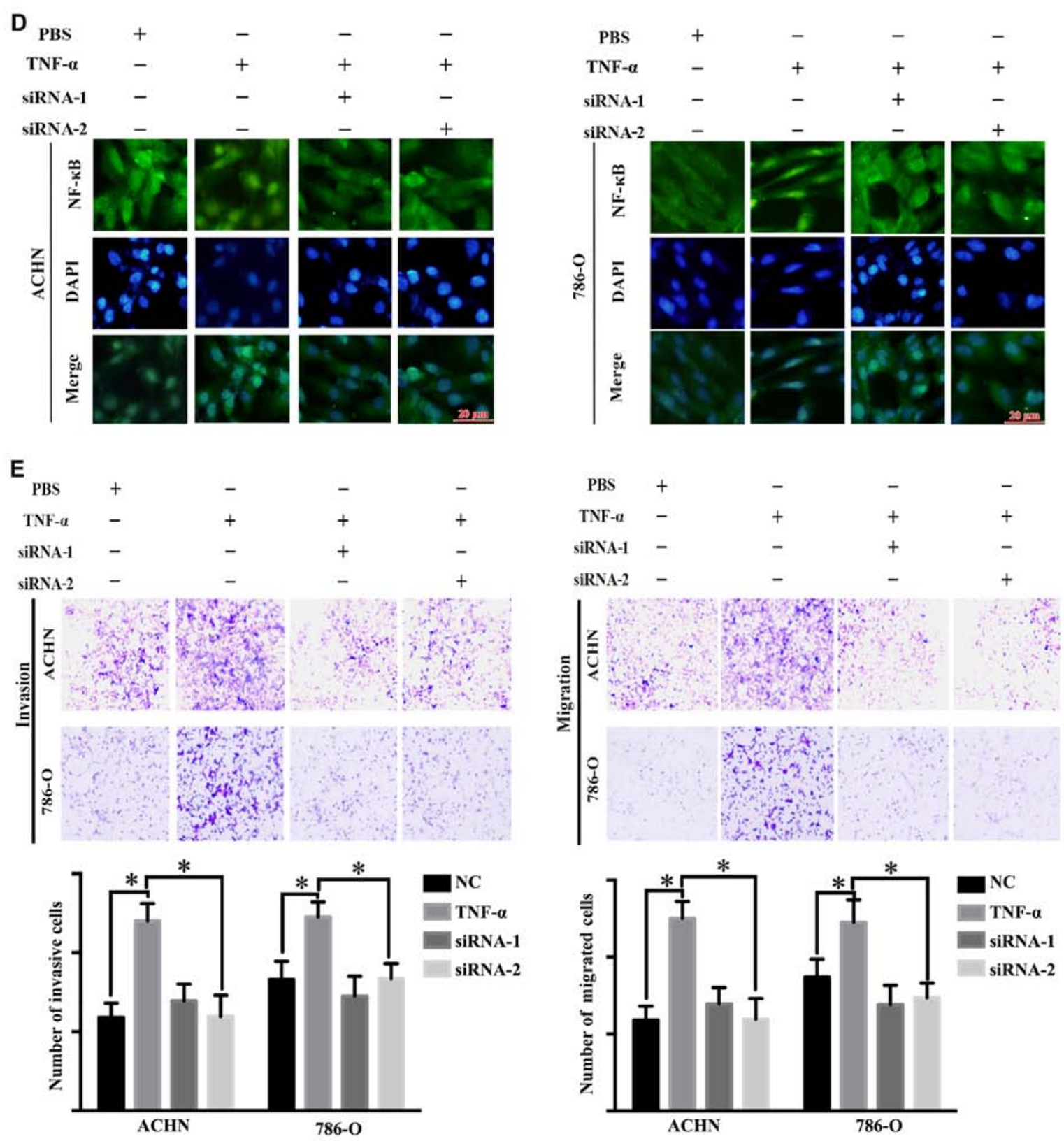

Figure 5. Continued. (D) Nuclear immunofluorescence intensity of NF-kB was reduced in the SNHG15 siRNA groups compared with in the NC groups (E) Cell migration and invasion were altered among the various groups following TNF- $\alpha$ stimulation and siRNA transfection (magnification, $\mathrm{x} 40$ ). " $\mathrm{P}<0.01$. EMT, epithelial-mesenchymal transition; NC, negative control; NF-кB, nuclear factor- $\kappa \mathrm{B}$; siRNA, small interfering RNA; SNHG15, small nucleolar RNA host gene 15 ; TNF- $\alpha$, tumor necrosis factor- $\alpha$; ZEB1, zinc finger E-box-binding homeobox 1.

elements could specifically bind SNHG15. In addition, NF- $\kappa \mathrm{B}$ is able to induce the expression of Snaill, Slug and ZEB1, and promote the EMT process (16-18). Therefore, it was hypothesized that SNHG15 may affect the NF-kB signaling pathway in RCC. Using western blotting, the total expression of p50 was detected in RCC cells post-transfection with SNHG15 and NC siRNAs; however, there were no differences detected between the SNHG15 and NC groups ( $\mathrm{P}>0.05$; Fig. 5A). These findings indicated that knockdown of SNHG15 may not affect p50 expression. Subsequently, the present study investigated whether SNHG15 may affect NF- $\kappa$ B transportation to the nucleus. To analyze this, 786-O and ACHN cells were transfected with siRNA for $72 \mathrm{~h}$ and the nuclear/cytoplasmic expression of $\mathrm{NF}-\kappa \mathrm{B}$ was measured. NF- $\kappa \mathrm{B}$ nuclear expression was reduced in the SNHG15 siRNA groups, whereas NF- $\mathrm{kB}$ cytoplasmic expression was slightly increased $(\mathrm{P}<0.01 ;$ Fig. 5B). In addition, the expression levels of EMT markers were examined $(\mathrm{P}<0.01$; Fig. 5C); the expression levels of $\mathrm{N}$-cadherin and Vimentin were markedly increased under TNF- $\alpha$ stimulation, and were decreased in the SNHG15 siRNA groups. TNF- $\alpha$, as the activator of NF- $\mathrm{kB}$, may promote the EMT process; therefore, TNF- $\alpha$ stimulation was used to confirm whether knockdown of SNHG15 might weaken the pro-EMT function of NF- $\mathrm{kB}$. Furthermore, an immunofluorescence assay was performed to further confirm whether SNHG15 may affect the NF- $\mathrm{BB}$ signaling pathway. The results demonstrated that, in spite of TNF- $\alpha$ stimulation, the nuclear fluorescence intensity of NF- $\kappa B$ was reduced in the SNHG15 siRNA groups compared with in the NC groups $(\mathrm{P}<0.01$; Fig. 5D). In addition, Transwell assays were conducted to detect migration and invasion under TNF- $\alpha$ 
stimulation. The results indicated that stimulation with TNF- $\alpha$ strengthened RCC migration and invasion; however, knockdown of SNHG15 was able to weaken this influence $(\mathrm{P}<0.01 ;$ Fig. $5 \mathrm{E})$. In conclusion, $\mathrm{SNHG15}$ may regulate the $\mathrm{NF}-\kappa \mathrm{B}$ signaling pathway, in order to promote migration and invasion.

\section{Discussion}

It has been reported that dysregulation of lncRNAs is closely associated with the development and progression of cancer (19). The present study revealed that SNHG15 may act as an onco-lncRNA in RCC, and the results revealed that it may be involved in the $\mathrm{NF}-\kappa \mathrm{B}$ signaling pathway, by inducing nuclear translocation of $N F-\kappa B$. To the best of our knowledge, the present study is the first to demonstrate the biological function of SNHG15 in RCC.

The IncRNA-SNHG family has been associated with tumorigenesis, metastasis and other cell functions. SNHG7 promotes lung cancer cell proliferation, migration and invasion, and inhibits apoptosis by enhancing Fas apoptotic inhibitory molecule 2 expression (20). Based on bioinformatics analysis, SNHG8 has been suggested as a potential biomarker and drug target candidate for gastric cancer, and is associated with Epstein-Barr virus (21). SNHG16 is regulated by the Wnt pathway in colorectal cancer and serves a role as a competing endogenous (ce)RNA in lipid metabolism. Knockdown of SNHG16 results in increased apoptosis and impaired migration (22). Furthermore, SNHG16 expression has been reported to be frequently increased in breast cancer tissues and to significantly promote breast cancer cell migration (23); SNHG16 exerts its effects by acting as a ceRNA, competitively binding miR-98 with E2F transcription factor 5 protein. SNHG14 increases the expression of phospholipase A2 group IVA via the inhibition of miR-145-5p, which may result in the activation of microglia in cerebral infarction (24). Under c-MYC-induced upregulation, SNHG12 regulates cell proliferation, apoptosis and migration in triple-negative breast cancer (25). Furthermore, SNHG15 expression is significantly upregulated in hepatocellular carcinoma and gastric cancer $(13,26)$. Tani and Torimura reported that SNHG15 may become a surrogate indicator for the chemical stress response, and may enhance human cell susceptibility to death under various stressors (27). However, the biological function of SNHG15 in RCC remains unknown.

$\mathrm{NF}-\kappa \mathrm{B}$ serves important pathological roles in the development and progression of cancer (28); however, whether IncRNAs regulate its activation, or how lncRNAs and NF- $\kappa \mathrm{B}$ interact with each other, remains under study. $\mathrm{NF}-\kappa \mathrm{B}-$ interacting lncRNA (NKILA), which is upregulated by $N F-\kappa B$, has been identified to bind with $\mathrm{NF}-\kappa \mathrm{B} / \mathrm{I} \kappa \mathrm{B}$, and directly masks phosphorylation motifs of $I \kappa B$, thereby inhibiting $I \kappa B$ kinase-induced $\mathrm{I} \kappa \mathrm{B}$ phosphorylation and $\mathrm{NF}-\kappa \mathrm{B}$ activation. Notably, NKILA is necessary to prevent NF- $\kappa \mathrm{B}$ pathway overactivation in inflammation-stimulated breast epithelial cells (29). Furthermore, ectopic expression of HOTAIR mediates $\mathrm{NF}-\kappa \mathrm{B}$ activation during the DNA damage response; HOTAIR induces activation of NF- $\kappa \mathrm{B}$ and prolongs NF- $\kappa \mathrm{B}$ activation in recurrent platinum-resistant ovarian tumors (30).

$\mathrm{NF}-\kappa \mathrm{B}$ is a transcription factor, which can enter the nucleus and bind specific promoter sequences of EMT-associated proteins, including Snail and Slug, thus promoting migration and invasion (31,32). The present study analyzed TCGA and GEO datasets to compare the expression of SNHG15 in RCC and normal tissues, and revealed that SNHG15 was markedly upregulated in RCC. To confirm this finding, the expression levels of SNHG15 were detected in 96 pairs of RCC samples. Notably, the expression levels of SNHG15 were upregulated in tumor samples compared with in normal tissues. In addition, SNHG15 expression was increased in RCC cell lines compared with in the normal HK-2 cell line. A Kaplan-Meier analysis confirmed that patients with a higher SNHG15 level exhibited shorter overall survival compared with the lower expression group. To further investigate the function of SNHG15 in RCC, cell biological function assays were conducted following knockdown of SNHG15. The results demonstrated that silencing SNHG15 expression led to significant inhibition of cell proliferation, invasion and migration. Furthermore, EMT biomarkers were investigated in the SNHG15 siRNA and NC groups using western blotting. The protein expression levels of EMT markers were significantly downregulated in the SNHG15 siRNA groups. In addition, bioinformatics analysis indicated that $\mathrm{NF}-\kappa \mathrm{B}$ could specifically bind to SNHG15. Therefore, nuclear proteins were extracted and western blotting was performed. The findings indicated that knockdown of SNHG15 contributed to a decrease in NF- $\mathrm{KB}$ translocation to the nucleus. An immunofluorescence assay also confirmed that SNHG15 may regulate the NF- $\mathrm{BB}$ signaling pathway.

In conclusion, the expression levels of SNHG15 were increased in RCC tissues and cell lines. The present findings indicated that SNHG15 may regulate the proliferation, migration and invasion of RCC cells via regulation of the NF- $\kappa \mathrm{B}$ signaling pathway. The findings of this study may have diagnostic and therapeutic implications; these data may improve understanding regarding RCC pathogenesis and progression, offer a novel insight into lncRNA interactions with proteins, and provide information regarding the biological and molecular functions of lncRNA.

\section{Acknowledgements}

Not applicable.

\section{Funding}

The present study was supported by grants from the National Natural Science Foundation of China (grant no. 81672525), the Liaoning Nature Science Fund (grant no. 201602830), the Shenyang Plan Project of Science and Technology (grant no. 17-230-098), Liaoning Distinguished Professor [grant no. (2012)145], the Shenyang Clinical Medicine Research Center [grant no. (2017)76], the National Natural Science Foundation of China (grant no. 81672523) and the Doctoral Scientific Research Foundation of Liaoning Province (grant no. 20141038).

\section{Availability of data and materials}

The datasets used and/or analyzed during the current study are available from the corresponding author on reasonable request.

\section{Authors' contributions}

YD designed and performed most of the experiments. YZ was involved in designing the bioinformatics analysis, and 
drafting and modifying the manuscript. $\mathrm{ZZ}$ participated in designing and performing the EdU proliferation and Transwell experiments. ZeL, JB, ZhL and XL collected tissue samples and clinical information of the 96 patients with RCC, and contributed to revision of the manuscript and figures. XY and MY conducted reverse transcription-quantitative polymerase chain reaction analyses to detect the relative expression levels of SNHG15 in 96 pairs of tumor/adjacent normal tissues, and statistically analyzed the differential expression of SNHG15 in tumor/adjacent normal tissues. CK acquired funding, established the urology laboratory, provided the required equipment and instruments, supervised the immunofluoresence assay, contributed to the critical reading of the manuscript, generated the figures, and gave final approval of the manuscript.

\section{Ethics approval and consent to participate}

The present study was approved by the Ethics Committee on Human Research of the First Affiliated Hospital of Chinese Medical University (Shenyang, China), and written informed consent was obtained from all patients.

\section{Consent for publication}

Written informed consent was obtained from all patients.

\section{Competing interests}

The authors declare that they have no competing interests.

\section{References}

1. Ljungberg B, Campbell SC, Choi HY, Jacqmin D, Lee JE, Weikert S and Kiemeney LA: The epidemiology of renal cell carcinoma. Eur Urol 60: 615-621, 2011.

2. Chen W, Zheng R, Baade PD, Zhang S, Zeng H, Bray F, Jemal A, Yu XQ and He J: Cancer statistics in China, 2015. CA Cancer J Clin 66: 115-132, 2016.

3. Cancer Genome Atlas Research Network: Comprehensive molecular characterization of clear cell renal cell carcinoma. Nature 499: 43-49, 2013.

4. Mercer TR, Dinger ME and Mattick JS: Long non-coding RNAs: Insights into functions. Nat Rev Genet 10: 155-159, 2009.

5. Wilusz JE, Sunwoo H and Spector DL: Long noncoding RNAs: Functional surprises from the RNA world. Genes Dev 23: 1494-1504, 2009.

6. Geisler S and Coller J: RNA in unexpected places: Long noncoding RNA functions in diverse cellular contexts. Nat Rev Mol Cell Biol 14: 699-712, 2013.

7. Martens-Uzunova ES, Böttcher R, Croce CM, Jenster G, Visakorpi $\mathrm{T}$ and Calin GA: Long noncoding RNA in prostate, bladder, and kidney cancer. Eur Urol 65: 1140-1151, 2014.

8. Hajjari M and Salavaty A: HOTAIR: An oncogenic long noncoding RNA in different cancers. Cancer Biol Med 12: 1-9, 2015

9. Hirata H, Hinoda Y, Shahryari V, Deng G, Nakajima K, Tabatabai ZL, Ishii N and Dahiya R: Long Noncoding RNA MALAT1 Promotes Aggressive Renal Cell Carcinoma through Ezh2 and Interacts with miR-205. Cancer Res 75: 1322-1331, 2015.

10. Han Y, Liu Y, Nie L, Gui Y and Cai Z: Inducing cell proliferation inhibition, apoptosis, and motility reduction by silencing long noncoding ribonucleic acid metastasis-associated lung adenocarcinoma transcript 1 in urothelial carcinoma of the bladder. Urology 81: 209.e1-209.e7, 2013.

11. Ying L, Chen Q, Wang Y, Zhou Z, Huang Y and Qiu F: Upregulated MALAT-1 contributes to bladder cancer cell migration by inducing epithelial-to-mesenchymal transition. Mol Biosyst 8: 2289-2294, 2012.

12. Serghiou S, Kyriakopoulou A and Ioannidis JPA: Long noncoding RNAs as novel predictors of survival in human cancer: A systematic review and meta-analysis. Mol Cancer 15: 50, 2016.
13. Chen SX, Yin JF, Lin BC, Su HF, Zheng Z, Xie CY and Fei ZH: Upregulated expression of long noncoding RNA SNHG15 promotes cell proliferation and invasion through regulates MMP2/ MMP9 in patients with GC. Tumour Biol 37: 6801-6812, 2016.

14. Livak KJ and Schmittgen TD: Analysis of relative gene expression data using real-time quantitative PCR and the 2(-Delta Delta $\mathrm{C}(\mathrm{T})$ ) method. Methods 25: 402-408, 2001.

15. von Roemeling CA, Radisky DC, Marlow LA, Cooper SJ, Grebe SK, Anastasiadis PZ, Tun HW and Copland JA: Neuronal pentraxin 2 supports clear cell renal cell carcinoma by activating the AMPA-selective glutamate receptor-4. Cancer Res 74: 4796-4810, 2014.

16. Julien S, Puig I, Caretti E, Bonaventure J, Nelles L, van Roy F, Dargemont C, de Herreros AG, Bellacosa A and Larue L: Activation of NF-kappaB by Akt upregulates Snail expression and induces epithelium mesenchyme transition. Oncogene 26: 7445-7456, 2007.

17. Chua HL, Bhat-Nakshatri P, Clare SE, Morimiya A, Badve S and Nakshatri H: NF-kappaB represses E-cadherin expression and enhances epithelial to mesenchymal transition of mammary epithelial cells: Potential involvement of ZEB-1 and ZEB-2. Oncogene 26: 711-724, 2007.

18. Criswell TL and Arteaga CL: Modulation of NFkappaB activity and E-cadherin by the type III transforming growth factor beta receptor regulates cell growth and motility. J Biol Chem 282: 32491-32500, 2007.

19. Prensner JR and Chinnaiyan AM: The emergence of lncRNAs in cancer biology. Cancer Discov 1: 391-407, 2011.

20. SheK, Huang J,Zhou H,Huang T, Chen G and He J: IncRNA-SNHG7 promotes the proliferation, migration and invasion and inhibits apoptosis of lung cancer cells by enhancing the FAIM2 expression. Oncol Rep 36: 2673-2680, 2016.

21. Huang T, Ji Y, Hu D, Chen B, Zhang H, Li C, Chen G, Luo X, Zheng XW and Lin X: SNHG8 is identified as a key regulator of epstein-barr virus(EBV)-associated gastric cancer by an integrative analysis of lncRNA and mRNA expression. Oncotarget 7: 80990-81002, 2016.

22. Christensen LL, True K, Hamilton MP, Nielsen MM, Damas ND, Damgaard CK, Ongen H, Dermitzakis E, Bramsen JB, Pedersen JS, et al: SNHG16 is regulated by the Wnt pathway in colorectal cancer and affects genes involved in lipid metabolism. Mol Oncol 10: 1266-1282, 2016.

23. Cai C, Huo Q, Wang X, Chen B and Yang Q: SNHG16 contributes to breast cancer cell migration by competitively binding miR-98 with E2F5. Biochem Biophys Res Commun 485: 272-278, 2017.

24. Qi X, Shao M, Sun H, Shen Y, Meng D and Huo W: Long noncoding RNA SNHG14 promotes microglia activation by regulating miR-145-5p/PLA2G4A in cerebral infarction. Neuroscience 348: 98-106, 2017.

25. Wang O, Yang F, Liu Y, Lv L, Ma R, Chen C, Wang J, Tan Q, Cheng Y, Xia E, et al: C-MYC-induced upregulation of lncRNA SNHG12 regulates cell proliferation, apoptosis and migration in triple-negative breast cancer. Am J Transl Res 9: 533-545, 2017.

26. Zhang JH, Wei HW and Yang HG: Long noncoding RNA SNHG15, a potential prognostic biomarker for hepatocellular carcinoma. Eur Rev Med Pharmacol Sci 20: 1720-1724, 2016.

27. Tani $\mathrm{H}$ and Torimura M: Identification of short-lived long non-coding RNAs as surrogate indicators for chemical stress response. Biochem Biophys Res Commun 439: 547-551, 2013.

28. Escárcega RO, Fuentes-Alexandro S, García-Carrasco M, Gatica A and Zamora A: The transcription factor nuclear factorkappa B and cancer. Clin Oncol (R Coll Radiol) 19: 154-161, 2007.

29. Liu B, Sun L, Liu Q, Gong C, Yao Y, Lv X, Lin L, Yao H, Su F, Li D, et al: A cytoplasmic NF- $\mathrm{BB}$ interacting long noncoding RNA blocks I $\mathrm{B}$ phosphorylation and suppresses breast cancer metastasis. Cancer Cell 27: 370-381, 2015.

30. Özeş AR, Miller DF, Özeş ON, Fang F, Liu Y, Matei D, Huang T and Nephew KP: NF- $\kappa \mathrm{B}-\mathrm{HOTAIR}$ axis links DNA damage response, chemoresistance and cellular senescence in ovarian cancer. Oncogene 35: 5350-5361, 2016.

31. Min C, Eddy SF, Sherr DH and Sonenshein GE: NF-kappaB and epithelial to mesenchymal transition of cancer. J Cell Biochem 104: 733-744, 2008.

32. $\mathrm{Yu} \mathrm{L}, \mathrm{Mu} \mathrm{Y}, \mathrm{Sa} \mathrm{N}$, Wang $\mathrm{H}$ and $\mathrm{Xu} \mathrm{W}$ : Tumor necrosis factor $\alpha$ induces epithelial-mesenchymal transition and promotes metastasis via NF- $\kappa \mathrm{B}$ signaling pathway-mediated TWIST expression in hypopharyngeal cancer. Oncol Rep 31: 321-327, 2014. 